\title{
Medievalista
}

Online

$30 \mid 2021$

Número 30

Estudio y edición de La fazienda de UltramarTese de Doutoramento

em Literatura, apresentada à Faculdade de Filosofia e Letras da

Universidade de Buenos Aires (Argentina), em Abril de 2019.

Orientação da Professora Doutora Carina Zubillaga

\section{Geografía e imaginario bíblico medieval}

Estudio y edición de La fazienda de Ultramar. Tese de Doutoramento em Literatura, apresentada à Faculdade de Filosofia e Letras da Universidade de Buenos Aires (Argentina), em Abril de 2019. Orientação da Professora Doutora Carina Zubillaga

\section{Melisa Marti}

\section{(2) OpenEdition}

Journals

Edición electrónica

URL: https://journals.openedition.org/medievalista/4583

DOI: 10.4000/medievalista.4583

ISSN: 1646-740X

Editor

Instituto de Estudos Medievais - FCSH-UNL

Referencia electrónica

Melisa Marti, «Geografía e imaginario bíblico medieval», Medievalista [En línea], 30 | 2021, Publicado el 01 julio 2021, consultado el 24 julio 2021. URL: http://journals.openedition.org/medievalista/4583; DOI: https://doi.org/10.4000/medievalista.4583

Este documento fue generado automáticamente el 24 julio 2021.

Mediavalista está licenciado com uma Licença Creative Commons - Atribuição-NãoComercial 4.0 Internacional. 
Estudio y edición de La fazienda de UltramarTese de Doutoramento

em Literatura, apresentada à Faculdade de Filosofia e Letras da

Universidade de Buenos Aires (Argentina), em Abril de 2019.

Orientação da Professora Doutora Carina Zubillaga

\section{Geografía e imaginario bíblico medieval}

Estudio y edición de La fazienda de Ultramar. Tese de Doutoramento em Literatura, apresentada à Faculdade de Filosofia e Letras da Universidade de Buenos Aires (Argentina), em Abril de 2019. Orientação da Professora Doutora Carina Zubillaga

\section{Melisa Marti}

\section{NOTA DEL EDITOR}

Data recepção do artigo / Received for publication: 16 de Outubro de 2020

1 La tesis doctoral aquí presentada tuvo por objetivo elaborar una edición crítica de La fazienda de Ultramar y estudiar el texto a partir de un enfoque filológico e históricocultural. En esta oportunidad, intentaré hacer un recorrido por los principales problemas e interrogantes que surgieron a la hora de estudiar la obra y de fijar el texto para su edición, y describiré cómo estos hicieron que definiera con mayor precisión el objeto de esta tarea de reconstrucción textual.

2 La fazienda de Ultramar es la primera obra extensa en prosa castellana no notarial, aparecida alrededor de 1230 . Se trata de un texto conservado en un manuscrito único que incluye una traducción del Antiguo Testamento -y, en menor medida, del Nuevo Testamento- donde se resaltan y amplifican algunos pasajes y se omiten y reordenan otros tantos. La motivación detrás de la selección de libros canónicos fue la geografía de Tierra Santa, que orienta el recorrido por los relatos bíblicos a la manera de las guías de peregrinos o itinerarios medievales. 
El manuscrito fue descubierto hace poco más de cincuenta años, cuando inició un recorrido por distintos enfoques críticos que lo describieron desde diferentes ángulos y perspectivas. El texto que inauguró su estudio ${ }^{1}$ hablaba de una "Biblia romanceada e itinerario bíblico medieval", pero ya desde el comienzo estas categorías se vieron problematizadas y cuestionadas sin dar lugar a una descripción acabada del texto. La escasa bibliografía específica, en consecuencia, se centró sobre todo en la lengua del manuscrito y en transmitir los pocos datos que conocemos acerca de la datación y la autoría.

4 En la tesis, la investigación se plasmó en un estudio preliminar cuyos capítulos se plantean como respuestas a los interrogantes que el lector podría formularse a la hora de acceder a un texto de estas características (muchas de ellas, comunes e inherentes a los textos producidos en la primera época de la literatura castellana). Estos interrogantes y sus respuestas posibles están estrechamente ligados con el trabajo ecdótico, ya que los ejes analizados en el transcurso de la investigación han sido determinantes a la hora de tomar decisiones con respecto al perfil de edición que propongo. Por lo tanto, los apartados y anexos están orientados a servir de puerta de acceso a La fazienda de Ultramar: debido a que el enfoque al que sometimos el texto a lo largo de esta investigación ha sido histórico-cultural y filológico, el análisis de sus condiciones de producción y recepción es, a grandes rasgos, lo que motiva la organización de los contenidos del estudio. En consecuencia, los primeros apartados, acerca del códice y su autor, apuntan a considerar la materialidad del texto para luego examinar su funcionamiento en contexto. El resto de los apartados, por su parte, tienen el objetivo de recomponer el sistema cultural en el que La fazienda de Ultramar circuló, por lo que el eje que los concatena es la consideración de la lengua del texto como vehículo de tradiciones culturales propias de un ámbito social determinado.

5 Finalmente, el trabajo incluye una serie de anexos para orientar el conocimiento de la lengua y de los espacios descriptos a lo largo de la obra, así como de su relación con su fuente principal, la Biblia; estos anexos son un glosario de los términos que pueden resultarle extraños al lector (o que aparecen aquí aludiendo a una acepción ya perdida), un cuadro con los topónimos mencionados en el texto a la par de sus nombres modernos, y un esquema de los libros bíblicos incluidos en La fazienda.

6 Por las razones que acabo de exponer, a lo largo de esta exposición intentaré sintetizar algunas de las problemáticas principales a las que me enfrenté al momento de realizar el estudio y edición de La fazienda de Ultramar: la datación del manuscrito y sus implicancias, las fuentes textuales y el proceso de traducción, la problemática del manuscrito único y la geografía como elemento estructurador.

\section{Datación del manuscrito e implicancias}

B Tanto la datación del códice como su autoría han sido objetos de debate desde su descubrimiento. El hecho de que el manuscrito esté encabezado por dos epístolas -que, a primera vista, facilitarían la atribución de la obra- oscurece e ilumina alternativamente nuestro conocimiento sobre el texto, ya que, aisladas de la información que nos proporciona el manuscrito en su materialidad y de sus condiciones de producción, circulación y recepción, son engañosas; sin embargo, es posible que encierren pistas acerca del proceso de composición de la obra.

9 La tarea de traducción del texto bíblico habría sido encomendada a Almeric o Almerich, a quien se adjudica la autoría de La fazienda, por Raimundo de Sauvetat, nombrado 
como Remont; así lo indica el intercambio epistolar antedicho. El primero, también conocido como Almerico Malafaida, fue el tercer patriarca de Antioquía en la segunda mitad del siglo XII. Raimundo, segundo arzobispo de Toledo, fue un reconocido patrocinador de la Escuela de Traductores. Si superponemos los períodos en los que estos interlocutores ejercieron las funciones que declaran en las epístolas, el texto debería haber sido redactado entre 1142 y 1152. Esta es la hipótesis defendida por Moshé Lazar, el primer editor de la obra, quien argumenta que la lengua del manuscrito es próxima a la del Poema de Mio Cid (tomando como fecha de composición el año 1140), y sostiene que el tipo de letra avala este fechado del manuscrito (mediados del siglo XII).

De ser auténticas estas epístolas, sin embargo, el texto que contiene el manuscrito sería la traducción de un original seguramente en latín, posibilidad no contemplada por Lazar, quien no hace distinción entre la obra original y la copia conservada. Esta hipótesis se sustenta sobre la base de que la información lingüística e histórica que podemos obtener de él no se condice con los datos biográficos de los participantes de este intercambio epistolar: Raimundo fue un gran difusor de la tarea de traducción, pero principalmente tomando al latín como lengua de destino.

11 Por otra parte, dado que la obra refleja un estadio de la lengua castellana más cercano a las primeras décadas del siglo XIII y que parece improbable que Almerich haya elegido el castellano en lugar del francés, lengua que tenía en común con Raimundo, la datación propuesta originalmente pierde sustento.

12 A su vez, si se tienen en cuenta las fechas en que estos personajes históricos murieron, y si fuera cierto que ambos cultivaron una amistad en su "mancebía", significaría que el arcediano Almerich tuvo una vida extraordinariamente larga. Por lo tanto, los estudios que subsiguieron consideraron las cartas como apócrifas, y tomaron como fecha aproximada de composición de la obra las primeras décadas del siglo XIII. Las epístolas, por lo tanto, podrían haber sido incluidas para dar credibilidad al itinerario o para autorizar el texto.

13 Otros estudiosos del texto consideraron la posible existencia de un original en latín o en un dialecto occitano, que habría sido el texto encargado por el arzobispo. Esto explicaría, por ejemplo, algunos préstamos del occitano antiguo, como foldres (rayos), y de otros rasgos que demostrarían el origen gascón del texto.

14 Con todo ello, podemos concluir que Almerich no fue el autor del texto castellano y no es posible afirmar con certeza que haya sido el autor de una versión precedente en latín o romance. Más allá de esto, lo que sí es evidente es la presencia de un gran número de rasgos dialectales y préstamos del mozárabe, aragonés y catalán, además de las lenguas galorromances.

Por otra parte, el texto nos proporciona otros datos que permiten atrasar la fecha de composición. Entre ellos, se encuentran la mención a "Bermudo", Garmond de Picquigny (muerto en 1128). Las noticias de este patriarca de Jerusalén que aparecen en el texto alimentan la hipótesis de una fecha de redacción más reciente, ya que se refieren a la toma de Tiro y al Pactum warmundi, ocurridos alrededor de 1124. También encontramos una mención a una edificación que se encuentra sobre el mar de Galilea, El Gue Jacob, una fortaleza construida por la Orden del Temple en 1178. Esto no deja de ser llamativo, ya que el autor recurre a un topónimo de su época, cuando la Vulgata lo nombra Vadum Jacob. La referencia histórica más tardía es la de la Vera Cruz, 
desaparecida en 1187, que estuvo en el altar de la Santa Trinidad hasta la batalla de Hattin.

A su vez, encontramos una mención a un episodio conocido como Passio imaginis Christi, surgido en el siglo IV. Este narra la profanación de un crucifijo en Beirut por parte de un grupo de judíos que, al ver la maravilla que acontecía al brotar sangre y agua de la imagen, se convierten al cristianismo. Si bien este relato adquiere gran importancia ya en el II Concilio de Nicea, en el siglo VIII (cuando contribuye al triunfo de la iconodulia sobre la iconoclasia), alcanzó una mayor difusión en los siglos XII y XIII y se encuentra testimoniado en varias lenguas romances.

Por lo tanto, la evidencia interna parece retrasar la fecha de redacción del texto original al menos hacia las últimas décadas del siglo XII. El testimonio que conservamos, entonces, sería una copia de una traducción original en latín o dialecto occitano (o, como cabe sospechar, una copia de una copia, debido a los abundantísimos errores mecánicos que pueden observarse).

La evidencia lingüística, por su parte, permite retrasar la fecha del texto castellano a las primeras décadas del siglo XIII. Encontramos rasgos que aparecen también en Berceo y textos del mester de clerecía. Si bien es posible identificar algunos arcaísmos, la crítica se encargó de señalar que muchos de ellos persistían en textos aparecidos a comienzos del siglo XIII.

El análisis del contexto de producción y circulación de la obra fue, por supuesto, uno de los pasos necesarios para no forzar la lengua del texto y no proponer enmiendas innecesarias como consecuencia del desconocimiento del abanico dialectal que conforma la morfología y el léxico desplegados en el texto. Sucede lo mismo con el siguiente eje, las fuentes textuales, que proporcionan indicios que podrían validar tanto la hipótesis de un original en latín, como en occitano.

\section{Fuentes textuales y proceso de traducción}

21 La estructura de la obra está fundada en el pedido de su supuesto mecenas, quien solicitó un registro de los nombres de los lugares bíblicos en latín, hebreo y romance; de la distancia que los separaba; y de las "maravillas" obradas por Dios en dichos lugares. Estos intereses cobran forma en un texto complejo, cuya hibridez refleja el modo en que los géneros se gestaban a medida que el castellano maduraba como lengua literaria.

Como ya he adelantado, las fuentes principales de La fazienda son dos: de un lado, la Biblia; del otro, el conjunto de itinerarios o guías de peregrinos, con los que La fazienda forma una genealogía compleja y difícil de abarcar.

\subsection{La Biblia}

El cotejo de La fazienda y del texto bíblico demuestra el uso mayoritario de la Biblia hebrea como fuente principal. Así lo evidencian algunas elecciones gramaticales, notablemente las lexicales, pero también es posible detectar marcas desinenciales en los verbos que la conectan con el original hebreo: vemos, por ejemplo, la elección de la $3^{\circ}$ persona en singular en algunos verbos, cuando en latín se transmitieron en plural (algo que se respetó en las primeras traducciones de la Biblia). Pero hay otras diferencias muy interesantes y complejas que se vinculan con la interpolación de textos apócrifos, teológicos, litúrgicos y escolásticos, lo que en ocasiones se manifiesta en pasajes que no reproducen con exactitud el texto bíblico, sino que reflejan una tradición devocional más reciente y viva. Es lo que sucede en ocasión del encuentro 
entre Abraham y tres hombres en el camino en Mamré (Génesis, 18: 1-2), episodio que fue interpretado y glosado profusamente por su relevancia dogmática, al leerse como una prefiguración de la Santísima Trinidad. El autor de La fazienda no era ajeno a esta tradición, por lo que incorporó la frase "Por esto diz que tres vio él, uno adoró" (fol. $1 \mathrm{v})^{2}$.

Encontramos un problema similar en la transmisión de un pasaje crítico para las discusiones doctrinales: la traducción de Isaías, 7: 14, donde el texto latino alude a la Virgen que concebirá al Hijo de Dios (virgo), mientras que el texto hebreo menciona que será una mujer joven (almah, עַלִַָ). Dado que La fazienda en dos oportunidades traduce el pasaje haciendo mención de una manceba, podemos inferir que su redactor estaba trabajando sobre la base del texto hebreo, y que las citas en latín servían para ampliarla.

El texto hebreo, además, aparece en contadas ocasiones en citas textuales. Esto se vincula con el hecho de que el siglo en que se redactó el texto vio un incremento en la cantidad de hebraístas y de estudiosos que ya no dependían de las traducciones primitivas, por lo que no es de extrañar que sea posible identificar un vínculo estrecho entre La fazienda y el texto hebreo. En aquel momento, además, se incrementó la circulación de manuscritos en esta lengua y su presencia en bibliotecas cristianas.

La Vulgata, por su parte, aparece como un complemento del texto hebreo, y las citas en latín son mucho más abundantes. Sirven, sobre todo, para reafirmar la motivación de la redacción de la obra: la indagación en la toponimia veterotestamentaria, por lo que los nombres de lugares aparecen con sus distintas raíces. Estas citas, sin embargo, deben ser examinadas cuidadosamente, ya que se conectan con otra tradición textual muy presente en La fazienda, tal como veremos más adelante.

\subsection{Itineraria}

En cuanto al grupo de los itinerarios, la identificación de las fuentes no es tan sencilla: en varias oportunidades, la crítica señaló como posible fuente textual de este itinerario la descripción de Tierra Santa de Rorgo Fretellus, arcediano de Nazaret, cuyas dos redacciones aparecieron entre los años 1137 y 1148 y se transmitieron en unos sesenta manuscritos. Sin embargo, el hecho de que existan a su vez muchas diferencias entre ambos, que acercan La fazienda a otros itinerarios de la época con los que coincide (ya sea el de Juan de Wurzburgo, también en lengua latina, o las descripciones de Tierra Santa en lenguas vernáculas), dificulta la comprobación de la hipótesis de una fuente única, y pone de relieve el trabajo de nuestro autor como compilador de materiales textuales.

En efecto, el alto grado de codificación y uniformidad que podemos encontrar en estos textos hace muy dificultosa la tarea de identificación de una fuente única, tarea que no parece pertinente una vez que se pone en perspectiva el entramado textual de $L a$ fazienda y la compilación y selección de fuentes. A su vez, la hipótesis de que La fazienda sea una traducción de un original escrito en un dialecto occitano me impulsó a profundizar en su posible conexión con textos en romance. Así, el cotejo con itinerarios franceses (tales como Les pelerinaiges por aler en Iherusalem, de las primeras décadas del siglo XIII; La Sainte cité de Iherusalem, les Saints Lieux \& le pelerinage de la Terre, de 1261; y Les chemins et les pelerinages de la Terre Sainte, de 1265$)^{3}$ muestra que existen muchas coincidencias en los modos de describir algunos lugares, pero también errores conjuntivos que podrían implicar una filiación. 

que tienden a reducir la cantidad de fuentes a las que habría recurrido el autor de $L a$ fazienda para redactar su itinerario.

\subsection{Repertorio litúrgico}

La falta de certeza acerca del stemma de La fazienda y si verdaderamente existió una versión latina previa nos conduce a preguntarnos por las numerosas citas latinas que el autor optó por no traducir, y que funcionan como indicadores de la procedencia de un episodio determinado. Es por eso que se las introduce con la frase "donde dice": "Onde diz 'missus de valle Ebron venit in Sichem”' (fol. 1v).

Estas frases resultan muy llamativas, sobre todo porque muchas veces están incompletas o no están del todo relacionadas con el episodio que motiva su inclusión. Si el autor traducía una versión latina, ¿por qué mantuvo estas frases en su lengua original? ¿Fueron agregadas durante la redacción en castellano o estaban presentes en la redacción previa (latina o francesa)? ¿Qué las distingue de otras frases, incluso de las de mayor peso dogmático, que se transmitieron en romance? La razón detrás de este procedimiento se vincula con la procedencia de estas citas, que se creía que eran bíblicas. Si bien una parte de ellas lo es, muchas pertenecen, en realidad, al repertorio litúrgico, lo que explica que no hayan sido traducidas, ya que la comunidad cristiana las retenía en su memoria por vía auditiva, al oírlas en las ceremonias religiosas.

Un ejemplo lo constituye la frase "Rubrum quem videraz" (fol. 12r), que Moshé Lazar enmendó como "Videbat quod rubus, arderet", tal como aparece en la Biblia (Éxodo, 3: 2). El rastreo de esta cita nos revela que la frase a la que se refiere el autor de La fazienda es un verso del antifonario laudatorio correspondiente al oficio de la Virgen María.

La inclusión de estos versos litúrgicos nos remite a los modos de integrar la Biblia a las ceremonias religiosas, en las que el entretejido de citas constituía una forma de exégesis. Es decir, cantar y leer palabras de la Biblia combinándolas o alternándolas con textos ajenos a ella las ubicaba en contextos nuevos, lo que les otorgaba nuevas capas de sentido. Por lo tanto, la selección y combinación de textos bíblicos en los cánticos y lecturas se vuelve un sistema de interpretación que concede múltiples sentidos al texto sagrado. El autor de La fazienda, entonces, estaría recurriendo al procedimiento inverso, al incorporar frases tomadas de antifonarios a los pasajes bíblicos. Sus modos de construir nuevos sentidos, por supuesto, son tan pertinentes como los ya mencionados, y desconocerlos anularía un dispositivo interpretativo que ubica a $\mathrm{La}$ fazienda en un complejo sistema de citas y un modelo de generación de sentido estrictamente medieval.

3 Las operaciones sobre las fuentes textuales hasta aquí descriptas ${ }^{4}$ nos conducen a considerar la traducción a la que el autor de nuestro texto somete a la Biblia como un fenómeno histórico, delineado por las condiciones propias tanto del ámbito de la producción como de la recepción. Se trata, entonces, de un verdadero proceso de reescritura en el que el traductor se apropia de las fuentes para adaptarlas a su proyecto compositivo, y que involucra operaciones de selección y compilación de fuentes que el traductor rejerarquiza. Es decir, a los textos fuentes se le asigna una funcionalidad orientada al contexto de recepción.

\section{La problemática del manuscrito único}

El manuscrito conservado presenta varias características que dificultaron su estudio y edición. A las ya mencionadas, entre las que se destacan las citas en tres lenguas 
antiguas (latín, hebreo y arameo), se suman un gran número de errores paleográficos y loci critici (por supuesto, esperables), una multitud de aragonesismos y vocablos de origen dudoso, folios desordenados y pasajes corrompidos o atacados por la humedad.

Para encarar la edición de este codex unicus, procuré no intervenir el texto cuando presentara diferencias con respecto al Antiguo Testamento, a diferencia de lo que pude observar en la edición de Moshé Lazar. A modo de ejemplo, refiero el pasaje que corresponde al décimo mandamiento: "Non cobdicies cosa de to vezino ni cobdicies mugier de to próximo, ni su manceba, ni so buey, ni so asno, ni su mula, ni nulla cosa de to vezino" (fol. 18v). Lazar sustituye el primera cosa por casa, tal como se desprende del decálogo tradicional. Sin embargo, la lección del manuscrito es coherente y su interpretación es completamente válida. En este caso, y en muchos otros, no intervengo la transcripción, sino que respeto la lección manuscrita.

Como ya adelanté, los ejes analizados aquí contribuyeron a que superara algunos de los obstáculos propios de los manuscritos únicos. A modo de ejemplo, me remito a las citas latinas que el autor de La fazienda incluyó a lo largo del texto (que, como ya adelanté, provienen del repertorio litúrgico). El desconocimiento del entramado de fuentes diversas que constituye la obra hizo que Lazar las enmendara insistentemente para ajustarlas al texto de la Vulgata. Así, por ejemplo, la frase "At illi relictis retibus et navi secuti sunt eum" (fol. 34v), que es en realidad un verso de introito, es erróneamente identificada por Lazar como una mala copia de un versículo del Evangelio según San Mateo y justifica su enmienda conectando este fragmento con el pasaje correspondiente a esta escena según Marcos, 1: 20. Por lo tanto, el rastreo de las fuentes respaldó la decisión de no intervenir el texto en pasajes particularmente enigmáticos.

Otro de los problemas que están directamente vinculados con la inexistencia de otros testimonios de la obra es el desorden de folios que va desde el 54 hasta el 64. El modo en que Lazar intenta subsanarlo no tiene una justificación enteramente clara si se tiene en cuenta la materialidad del manuscrito, ya que en ocasiones reubica fragmentos que no evidencian un desorden en los cuadernos. Por eso opté por intervenir el texto sólo cuando la continuidad del relato estuviera severamente comprometida; es decir, cuando se rompiera una estructura sintáctica. Como La fazienda se caracteriza por intercalar episodios y por la elipsis, que en varias ocasiones interrumpe la narración, no consideré apropiado reordenar perícopas cuya distribución no parecía deberse a un problema mecánico de transmisión textual.

Una vez más, vemos cómo se torna necesario conocer el contexto de circulación de la obra, así como las condiciones materiales de producción, para superar algunas de las dificultades relacionadas con su transmisión en un único manuscrito.

\section{La geografía como elemento estructurador}

En La fazienda de Ultramar, la matriz ordenadora del universo bíblico está dada por la geografía de Tierra Santa, tomando como referencia las guías de peregrinos a Jerusalén. Como indica el título de esta tesis, este aspecto fue el motor principal de mi investigación doctoral. Al respecto, cabe aclarar que el estudio de La fazienda de Ultramar y su puesta en correlación con otros itinerarios muestran que el recorrido geográfico es un artificio narrativo, una herramienta generadora de sentidos que no pretende servir de guía real para una excursión a Tierra Santa.

Por otra parte, el análisis de las representaciones geográficas presentes en el texto no sólo es importante por su relación con la estructura y organización narrativa de la obra, 
sino también por reflejar el conocimiento geográfico de la época, en la que la Biblia se tomaba como autoridad máxima para la construcción del espacio y determinaba la manera en que el hombre interactuaba con él; por lo tanto, el estudio de La fazienda también nos permite establecer una red de alusiones con otros textos contemporáneos que construyen espacios simbólicos a partir de la Escritura. Resulta pertinente retomar lo que Michel Foucault ${ }^{5}$ denominó "espacio de localización": los espacios están jerarquizados, categorizados en sagrados y profanos, cerrados y abiertos, y, sobre todo, están fijos, ajenos a toda noción de relatividad y de perpetuo movimiento e inestabilidad que se alcanzó en una etapa posterior del conocimiento cosmológico. Considero que la forma de representar la geografía en textos de este tipo responde a esta forma de entender los espacios como fijos y absolutos, como eternamente marcados por los relatos que los atravesaron. A su vez, resultan pertinentes las operaciones analizadas por Michel De Certeau ${ }^{6}$, quien señala que el relato opera sobre los distintos lugares fundando espacios, por ejemplo, con la tumba de los héroes o con la resignificación de piedras, árboles u otros hitos por medio de las acciones de sujetos históricos.

Igualmente relevante resulta la noción de recorrido, en tanto acto de enunciación que opera como la descripción: se proporciona una camino que se visualiza como algo estático ("allí delant", "a parte de orient", "yuso sos" o "asuso sobre") o móvil ("allí por la ribera del mar va omne a..."). Este análisis me parece sumamente interesante para analizar un tipo de discurso en el que las descripciones visuales no abundan: la mayoría de las descripciones presentes en la obra no son largas digresiones cargadas de imágenes sensoriales y de adjetivaciones, sino un entramado de localizadores espaciales, citas y referencias a personajes ficticios o históricos. Por eso, me inclino por clasificar los pasajes descriptivos, como De Certeau, en "mapas" y "recorridos", vinculados cada uno con operaciones descriptivas estáticas y móviles, en las que estas últimas determinan el estilo entero de la narración. La forma del recorrido condiciona a la del mapa, por lo que el ver está subordinado a un hacer, a cumplir con un itinerario. Incluso, como explica también De Certeau, los mapas propiamente dichos que fueron diseñados en este período incluían trazos de recorridos, indicaciones performativas que determinaban la representación geográfica: en las representaciones cartográficas del período un lugar existe porque es atravesado por la experiencia humana y en función de un recorrido.

En síntesis, me parece apropiado hablar, como De Certeau, de prácticas espacializantes, un concepto superador de la dicotomía narración/descripción que proponía la crítica para analizar el discurso de La fazienda de Ultramar y que desconoce el entramado textual que subyace a su estructura. Atendiendo a esta cuestión podremos ver el modo en que se proyecta la historia sobre la geografía, y se examinan las distintas capas de historia que cubren cada punto geográfico.

El hecho de que el desarrollo de la acción se encuentre imbricado con la descripción del espacio y que no pueda dividirse el texto en dos partes me condujo a evaluar cuál era el verdadero sentido de esa peregrinación que, en más de una ocasión, se vuelve impracticable por las grandes distancias que separan los hitos geográficos -distancias que, a su vez, se marcan de formas imprecisas-. Este punto se esclarece a la luz de la noción de homo viator que, junto con el de peregrinatio vitae, constituyen herramientas de interpretación útiles a la hora de analizar relatos de viajes medievales. Esta idea de que hombres y mujeres somos extranjeros en este mundo y que nuestro paso por la 
Tierra encarna una alienación (transitoria y orientada), una peregrinación universal hacia la redención, resignifica la motivación detrás de la tradición textual de los itinerarios. Todo itinerario se convierte en una manifestación providencial de un Orden, que se refleja también en el relato, concebido simbólicamente como un recorrido. Es por eso que La fazienda de Ultramar también puede ser entendida como una obra que es un viaje en sí mismo. No resulta casual, por lo tanto, que los últimos renglones se refieran a la venida del Mesías y a la promesa de la redención: "de Silo troa que venga Messías, que a Él es dada la realtad e a Él serán amansadas todas las yentes" (fol. 84v). La estructura circular de la obra, en la que Hebrón es punto de llegada y de salida, entonces, cierra el recorrido geográfico y también el textual, y resignifica el viaje como obra, como frecuentemente se hacía en la literatura del período. Es, también, la representación tipológica del cumplimiento de las profecías y de las promesas divinas, a partir de la cual se establecen conexiones entre las imágenes del exilio (del Paraíso) y del éxodo (de Egipto), y la búsqueda de la gracia divina.

El lector que recurre a una obra de este tipo, por lo tanto, no lo hace para servirse de la misma como una guía práctica sobre la que basarse para llevar a cabo un viaje físico, sino que el recorrido es espiritual, y está fundado en la identificación con los hombres y mujeres que, extraviados, buscaban la gracia perdida. El paso por el desierto, los asentamientos y montes, aúna a los personajes del Antiguo y del Nuevo Testamento, pero también a los lectores contemporáneos del autor de La fazienda.

\section{Conclusiones}

52 Lo hasta aquí expuesto me conduce a reafirmar las hipótesis de las que partí: el proceso de traducción, en tanto reelaboración de un discurso preexistente, conlleva una resignificación y una recontextualización de textos precedentes. A partir de esta noción, me aproximé al conocimiento del modo de transmisión del imaginario bíblico en lengua romance y del horizonte de expectativas de la sociedad ibérica del siglo XIII.

53 A su vez, comprobé que la caracterización formal y temática de la obra, comprendida en el marco de una contienda de prácticas discursivas, contribuye a una comprensión más cabal del período de emergencia de las letras castellanas. El trabajo con fuentes textuales de materias variadas y la labor de traducción que incorpora tanto el texto hebreo como la Vulgata para dar lugar a un texto nuevo son un espejo del modo en que la creación literaria medieval privilegiaba la integración de distintas tradiciones para generar nuevos sentidos.

Finalmente, corroboré que el estudio de las referencias geográficas presentes en La fazienda (ya no entendidas como digresiones, sino como partes integrales del texto) refleja un modo de reproducir la realidad espacial empírica que en ocasiones está en contienda con lo que transmitía la Escritura. Esto, en consecuencia, profundizó mi conocimiento de la percepción medieval del espacio.

La fazienda de Ultramar no sólo es el primer texto en castellano que refleja la preocupación por contextualizar la narración bíblica; también es una obra en la que las posibilidades y alcances de una lengua romance tienen una notable relevancia, ya que desde los primeros párrafos su autor le da un lugar central a la indagación lingüística acerca de los nombres de los lugares citados, y lo hace a partir del trabajo sobre el texto hebreo y el latino.

56 Finalmente, el estudio de estos aspectos y de otros que surgieron a la luz de esta investigación son una evidencia más de la necesidad de contar con una nueva edición 
que respete las particularidades del manuscrito y las motivaciones e intereses de su autor, y consiga recomponer el sistema cultural en que está inserta la obra.

\section{NOTAS}

1. LAZAR, Moshé - La fazienda de Ultra Mar: Biblia romanceada et itinéraire biblique en prose castillane du XII siècle. Salamanca: Universidad de Salamanca, 1965.

2. Esta y todas las citas de La fazienda de Ultramar pertenecen a mi transcripción.

3. MICHELANT, Henri ; RAYNAUD, Gaston - Itinéraires a Jérusalem et Descriptions de la Terre Sainte rédigés en français aux XI \& XIII ${ }^{e}$ siécles. Génova: Imprimerie Jules-Guillaume Fick, 1882.

4. Con ellas conviven otras tradiciones textuales de incidencia menor, tales como el discurso historiográfico, que se trasluce en las interpolaciones extrabíblicas que aluden a un contexto histórico más amplio; y también la literatura mitológica latina, que se manifiesta con la inclusión del mito de Píramo y Tisbe, cuya fuente exacta no he podido identificar, puesto que la versión de La fazienda es única en varios aspectos.

5. FOUCAULT, Michel -“Des espaces autres”. Architecture, Mouvement, Continuité 5 (Octobre 1984), pp. 46-49. Conferencia dictada en el Cercle des études architecturals, 14 de marzo de 1967.

6. DE CERTEAU, Michel - “Espacios' y 'lugares" y "Recorridos y mapas”. in La invención de lo cotidiano: 1. Artes de hacer. México, D. F.: Universidad Iberoamericana, 2006.

\section{AUTOR}

\section{MELISA MARTI}

IIBICRIT - Instituto de Investigaciones Bibliográficas y Crítica Textual (CONICET), Marcelo T. de Alvear 1694 , 1060; Buenos Aires; Argentina. melisa_marti@yahoo.com. https://orcid.org/ 0000-0002-8140-8918 